\title{
Facebook and political participation: Virtuous circle and participation intermediaries
}

Isidoropaolo Casteltrione, Queen Margaret University

\section{SUGGESTED CITATION}

Casteltrione, I. (2016), 'Facebook and political participation: Virtuous circle and participation intermediaries', Interactions: Studies in Communication \& Culture, 7: 2, pp. 177-196, doi: 10.1386/iscc.7.2.177_1

Link to the full text version of the article on IngentaConnect: http://www.ingentaconnect.com/contentone/intellect/iscc/2016/00000007/00000002/art00005;jse $\underline{\text { ssionid=19jso1k99g3cs.alice }}$

\begin{abstract}
Drawing from the results of a mixed-methods cross-national study focusing on Italy and the United Kingdom, this article explores how the contribution of Facebook to citizens' political participation varies in relation to pre-existing levels and different dimensions of political activity - namely, political expression and information vs political mobilization. The findings indicate that politically active individuals are the ones who take more advantage of the mobilization affordances of Facebook, whereas less politically active participants employ this social networking site mainly for political information. Activists consider Facebook as a key tool for the organization of political initiatives, enabling them to quickly communicate and coordinate, and to operate independently from traditional political institutions such as parties and trade unions. With regard to citizens who engage to a lesser degree in offline and online political activities, the informative power of Facebook
\end{abstract}


and its ease of use come into play. Facebook can, in fact, lower the thresholds of participation by making it more flexible. In addition, political information can reach less engaged users through the activity of participation intermediaries, activating a virtuous circle and potentially producing, in the long run, a mobilization effect.

\section{Keywords}

political participation

Facebook

political information

mobilization

mixed methods

Italy

United Kingdom 


\section{Introduction: Democratic deficit and political participation}

Over the last decade academic research has addressed the relationship between the Internet and politics (Chadwick and Horward 2009), with an increasing number of publications focusing on how this medium can affect citizens' political engagement and participation (Anduiza et al. 2009). Dahlgren (2009) indicates that this course in scholarship could be, in part, attributed to the fact that the rise of the Internet coincided with what has been described as 'democratic deficit' (Norris 2011) - namely, citizens' growing dissatisfaction with democratic political institutions and their detachment from the political process.

The democratic deficit characterizes many western democracies (Dalton 2004; Norris 2011; van Deth et al. 2007) and is particularly relevant to Italy and the United Kingdom, the two countries this article focuses on, where many citizens are dissatisfied with mainstream political parties and institutions (Curran et al. 2014), and participation in formal party politics has decreased sharply in the last two decades (Segatti 2006; Whiteley 2012). In this context, the Internet has been identified as a sort of 'magic elixir' able to increase citizens' participation and, consequently, to legitimize democratic governments (Stromer-Galley 2003).

Verba et al. (1995) describe voluntary political participation as the 'activity that has the intent or effect of influencing government actions - either directly by affecting the making or implementation of public policy or indirectly by influencing the selection of people who make those policies' (1995: 38). However, taking into account the emergence of new forms and logics of political participation (Bennett 1998; Bennett and Segerberg 2012; Norris 2002; Papacharissi 
2010), a more wide-ranging definition is developed in this article. This definition is essentially a hybrid one, arising from the combination of Verba et al.'s theorization (1995) and Christy's conceptualization of 'communication activities' (1987), with the latter described as a form of political participation not channelled through political institutions and reflecting a more individual interest and a psychological involvement in politics (e.g. certain forms of political discussion, following politics in the mass media, etc.). Hence, political participation will be intended here as the set of activities influencing or aiming to influence governments' actions and other individuals' political behaviours, and/or reflecting individuals' interest and psychological involvement in politics. Such a definition embraces what could be labelled as the mobilization dimension - influencing or aiming to influence governments' actions and other individuals' political behaviours - and the expression and information dimension - reflecting individuals' interest and psychological involvement in politics. It thus covers a wealth of participatory activities ranging from more traditional forms of participation, such as contacting a politician, to recently emerged forms, such as e-petitions or expressing political opinions online.

\section{Internet and political participation research: Optimists, normalizers and pessimists}

Three main schools of thought can be traced in the studies that have looked into the links between the Internet and citizens' political participation. At one end of the continuum there are

the optimists who argue that the Internet: promotes political participation by offering additional and convenient pathways to participation and mobilization; generates new forms of political 
engagement and participation; and engages audiences traditionally characterized by lower levels of political engagement and activity, such as young people, individuals with lower socioeconomic status, or isolated citizens (Bachmann and Gil de Zúñiga 2013; Hamilton and Tolbert 2012; Jensen 2013; Kavanaugh et al. 2008; Morris and Morris 2013; Rojas and Puig-i-Abril 2009).

At the other end of the continuum, there are the pessimists who describe the Internet as a distracting medium that can contribute to civic decline by inducing citizens to engage in online activities, and taking them away from more meaningful forms of participation (Nisbet and Scheufele 2004; Scheufele and Nisbet 2002; Zhang and Chia 2006).

The third school of thought is referred to as 'normalizers', according to whom the Internet has supplementary effects on political participation and engagement, reinforcing current participatory trends by aiding those citizens already interested in politics (Calenda and Meijer 2009; Calenda and Mosca 2007; Kenski and Stroud 2006; Krueger 2006; Moy et al. 2005). Among this group of scholars, there are some who perceive the reinforcement role of the Internet in a negative light. They believe that, by strengthening existing patterns of political engagement and participation, the Internet fortifies established power structures and widens the knowledge gap between politically active and less active citizens (Bimber 2001; Bonfadelli 2002; Brundidge and Rice 2009; Schlozman et al. 2010).

Research in this area has also produced contrasting evidence in relation to the impact of social networking sites (SNSs) on political participation. SNSs can be described as web-based services 
that 'allow individuals to present themselves, articulate their social networks, and establish or maintain connections with others' (boyd and Ellison 2007).

SNSs can aid and promote citizens' political participation (Baek 2015; Bond et al. 2012). Holt et al. (2013), Towner (2013) and Xenos et al. (2014) also provide evidence in support of the mobilization hypothesis and argue that SNSs could serve as a leveller of political participation between younger and older citizens, as youths' high usage of SNSs can compensate for their limited usage of traditional media to obtain political information.

In contrast to these findings, other studies show evidence of limited (Baumgartner and Morris 2010; Valenzuela et al. 2009) or even negative effects (Ancu and Cozna 2009; Fenton and Barassi 2011) of SNSs on political participation. Ancu and Cozna (2009), in a study that explored the reasons of the public's visits to MySpace profiles of the 2008 US Democratic and Republican primary candidates, found that users were attracted to MySpace mainly because of their desire of social interaction with other like-minded individuals, a type of usage negatively related to campaign involvement in the study. Fenton and Barassi (2011) contend that, in assessing the political potential of SNSs, differences between individual and collective forms of participation have to be considered, and also argue that SNSs tend to foster individualism and personal affairs, disconnecting individuals from the public terrain of political participation and guiding them away from the communality of collective political endeavour in favour of 'narratives of the self and forms of self-representation' (2011: 190). 
Other authors such as Baumgartner and Morris (2010) and Valenzuela et al. (2009) reject the idea that SNSs negatively affect political participation, suggesting instead that these platforms have limited or no effects on political participation. Baumgartner and Morris (2010) find that SNSs did not increase political interest and participation in young people who employ these platforms mainly to seek out supporting views. Similarly, focusing on the case of Facebook, Valenzuela et al. (2009) stress the limited contributions of SNSs to youths' political participation, arguing that these platforms are not the most effective tools to counteract youths' political disengagement.

Finally, there are a number of other investigations that back up the normalizers' stance and establish that politically engaged individuals get the most from SNSs (Carlisle and Patton 2013; Gustafsson 2012; Vesnic-Alujevic 2012; Vitak et al. 2011). Focusing on Facebook, Carlisle and Patton (2013) found that during the 2008 US Democratic and Republican primaries and General Election the public had a limited engagement in political activity via Facebook and that political interest strongly influenced Facebook political participation. These findings are supported by Vesnic-Alujevic (2012) and Gustafsson (2012). The first indicates that the more people were involved in politics offline, the more they participated politically through their Facebook profile pages. Similarly, distinguishing between members and non-members of interest organizations, Gustafsson (2012) establishes that members consider SNSs valuable tools for participation, but non-members generally refrain from sharing political views with their SNS friends and, despite being exposed to political content and requests for participation, prefer to remain passive. Finally, Vitak et al.'s study (2011) is arguably one of the most comprehensive efforts in SNSs and political participation research that recognizes the potential of Facebook as a political tool, 
stressing the strong link between the use of this SNS for political activity, political interest and offline political participation. In this sense, their research can be placed in the normalizers' group, suggesting that those who are already politically engaged seek multiple outlets for their political behaviours and that SNSs alone do not drive previously inactive individuals to political participation.

The review of research that looks into the contribution of the Internet and SNSs to political participation shows a lively debate in this area of study, mainly divided among what has been described as a continuum ranging from the optimists to the normalizers, and then to the pessimists. Where the normalizers' stance is the one gathering most support so far, the presence of a large number of studies supporting the optimists' and pessimists' arguments demonstrates that there is no conclusive evidence in this regard. Therefore, there is a need for further research in this area and for new approaches examining the links between digital technologies and citizens' political participation.

\section{Methodology: A sequential explanatory mixed methods study}

Most of the studies examining the contributions of digital technologies to political participation discussed in this article are quantitative in nature, and the great majority employ survey as research method (e.g. Ancu and Cozna 2009; Holt et al. 2013; Towner 2013; Vitak et al. 2011). 
While recently there has been a growth in qualitative investigations (Fenton and Barassi 2011; Gustafsson 2012; Storsul 2014; Vromen et al. 2015), mixed-methods (MM) studies are still scarce in this subject area, and only a few of the reviewed articles present a MM component (Kavanaugh et al. 2008; Valenzuela 2013; Valenzuela et al. 2012).

The research on which this article is based was inspired by the approach of Kavanaugh et al. (2008) and therefore it adopted a sequential-explanatory MM strategy, a research design that entails the collection and analysis of quantitative data followed by the collection and analysis of qualitative data. In this research design, qualitative data are employed to explain and build upon what surfaced in the first quantitative phase.

The data collection occurred in both Italy and the United Kingdom mostly during a non-electoral period, from March 2012 to December 2012, with the exception being local elections held in Italy (6-7 May, with a second round on 20-21 May) and the United Kingdom (3 May). Surveys were circulated on Facebook between March and June 2012, and interviews held between October and December 2012.

The overarching aim of this article is to explore how the contribution of Facebook to political participation varies in relation to pre-existing levels of political participation and different dimensions of political activity - for example, political expression and information vs political mobilization. 
The two related Research Questions (RQs) are:

RQ1: How does the contribution of Facebook to political participation vary in relation to preexisting levels of political activity?

RQ2: How does the contribution of Facebook vary in relation to two different dimensions of political activity - namely, political expression and information vs political mobilization?

\section{The quantitative phase}

In the first, quantitative, phase, self-administered online surveys explored participants' political participation. To this end, three general measures of political participation - namely, Facebook political participation, Internet political participation, and offline political participation - were developed. These measures are summated rating scales (Cronbach's $\alpha=0.948 ; 0.936 ; 0.927$ ) assessing the samples' participation in ten political activities, as displayed in Table 1. 


\begin{tabular}{|c|c|c|c|}
\hline Scale & & Items & Range \\
\hline $\begin{array}{l}\text { Facebook/Internet/offline } \\
\text { political participation }\end{array}$ & d) & $\begin{array}{l}\text { Organizing/participating in a political initiative, } \\
\text { meeting, rally and/or protest } \\
\text { Forming/joining a group or an organization } \\
\text { developed around politics } \\
\text { Soliciting others to support or oppose a particular } \\
\text { political party, candidate and/or initiative } \\
\text { Contacting a political party, candidate, government } \\
\text { department and/or local council } \\
\text { Learning about a political initiative, meeting, rally } \\
\text { and/or protest in which you took part } \\
\text { Learning about a political initiative, meeting, rally } \\
\text { discussions } 1 \\
\text { Expressing a political opinion } 2 \\
\text { Learning about a group or an organization } \\
\text { Consumption of political news }\end{array}$ & $\begin{array}{l}\text { From } 1 \\
\text { (Never) } \\
\text { to } 5 \\
\text { (Very } \\
\text { often) }\end{array}$ \\
\hline
\end{tabular}

Table 1: Facebook, Internet and offline political participation scales. 
Participants were asked how often (1=Never, 2=Rarely, 3=Sometimes, 4=Often, 5=Very often) in the last six months they engaged in each of the activities shown in Table 1 across three different channels of participation: Facebook; the Internet (excluding Facebook activity); and the offline world. The considered political activities were adapted from a number of political participation studies (Calenda and Meijer 2009; Kavanaugh et al. 2008; Kenski and Stroud 2006; Moy et al. 2005; Verba et al. 1995; Wang 2007). The idea was to focus on political activities that could be carried out on each of the considered political participation channels, in order to compare the samples' levels of political participation across Facebook, the Internet and the offline world. For this reason, activities relating exclusively to the Facebook and online dimensions, such as posting a link about politics, becoming a 'fan' of a political candidate or group, which were examined, for instance, in the study by Vitak et al. (2011), were not included in the survey.

In order to understand whether the contribution of Facebook to political participation varied according to the typology of political activity in question, the Facebook, Internet and offline political participation scales were then split into two sub-scales, each dealing with a different dimension of political participation: the mobilization dimension, which incorporates the activities $\mathrm{a}, \mathrm{b}, \mathrm{c}, \mathrm{d}$ and $\mathrm{e}$; and the expression/information dimension, encompassing the activities $f, g, h, i$ and $j$. 


\section{The qualitative phase}

Quantitative results were further explored in the second qualitative phase through a series of face-to-face/telephone interviews. The decision to include a subsequent qualitative phase derived from considerations on how qualitative data could usefully supplement and extend the quantitative analysis, illustrating and enhancing quantitative findings (Greene et al. 2001).

Thematic analysis was utilized to extract themes from the interviews. Using the qualitative data analysis software NVivo, a number of thematic categories were identified. The themes were established in a two-step process in which theory-driven and data-driven coding were combined (see Braun and Clarke 2006 - for a discussion of inductive and theoretical thematic analysis). In the first step, codes were developed on the basis of the review of the relevant academic literature (i.e. theory-driven coding) and quantitative results (i.e. data-driven coding). Finally, during the analysis of the qualitative data, further codes were added. Once the qualitative data were coded, relevant themes were identified. This was an iterative process in which themes evolved during the qualitative analysis. A list of themes relevant to the two RQs examined in this article can be found in Table 2. 


\begin{tabular}{|c|c|}
\hline Cluster & Themes \\
\hline Political participation & $\begin{array}{l}\text { - Relevance of political interest } \\
\text { - Involving new participants } \\
\text { - Facilitating participation } \\
\text { - Bringing politics into everyday life } \\
\text { - Accidental exposure to political information } \\
\text { - Virtuous circle }\end{array}$ \\
\hline $\begin{array}{l}\text { Expression/information } \\
\text { vs mobilization }\end{array}$ & $\begin{array}{l}\text { - More expression/information than mobilization } \\
\text { - Detachment from traditional politics } \\
\text { - Growing relevance of Facebook in activists' repertoires } \\
\text { - Promoting grassroots single-issue mobilization } \\
\text { - Interdependence between Facebook and offline political } \\
\text { participation }\end{array}$ \\
\hline
\end{tabular}

Table 2: Thematic analysis: Identified themes. 


\section{Sampling}

Compared to single-nation studies, sampling in cross-national research involves an extra layer of complexity (Lynn 2003). Issues can derive from the incomparability of the samples or sampling frames and the application of different sampling techniques and procedures (Milliman and Von Glinow 1998). The comparability of the samples can be enhanced by ensuring the equivalence of the population of each nation so as to generate matched samples (Lynn et al. 2007). Accordingly, matched samples were drawn for both the quantitative and qualitative phase of the present research.

To be eligible for the study, participants had to be Facebook users, between the age of 18 and 65 , and either British or Italian citizens (not necessarily residing in Italy and the United Kingdom). Underage users were excluded in order to avoid ethical issues. Pragmatically, users over 65 years were not considered because they represent a very small fraction of the Italian and British Facebook populations (Socialbakers 2012), and finding participants for this age group could have proved problematic.

Participants were recruited through a sequential quantitative-qualitative nested/parallel sampling strategy. In both phases, non-probability-sampling techniques were used. Snowball sampling was employed in the first quantitative phase in which Facebook was used as a recruitment platform. The researcher's Facebook contacts were initially targeted and asked to circulate the surveys among their networks. As non-probability sampling was adopted, the British sample (BS) and Italian sample (IS) cannot be considered representative of the target populations. Nonetheless, some measures were implemented to improve the samples' representativeness. 
First, the sizes of the two samples were calculated taking into account the sizes of the British and Italian Facebook populations at the time of data collection. Considering these figures, using a confidence interval of 95 per cent and allowing for a 7 per cent error, it was calculated that both the BS and the IS required 196 participants, for a total of 392 participants.

To further increase the representativeness of the recruited samples, a post-stratifying criterion was also applied. The application of weight after survey completion, in order to make the sample more representative of the target population, is a procedure often followed in Internet survey studies (Atkeson 2010) and it is indicated by Bhutta (2012) as a method particularly valuable for Facebook-drawn samples. Age was chosen as a stratifying criterion due to its relevance for political participation (see Quintelier 2007 - for a comprehensive account), and because it was the only demographic statistics provided about the British and Italian Facebook population by Socialbakers, the main source of Facebook statistics employed in this research.

In the qualitative phase of the study, two sub-samples of the quantitative samples were selected on the basis of participants' scores on a number of key variables (e.g. age, Facebook political participation, etc.). This purposive process, however, did not enable the recruitment of participants with certain profiles (i.e. young political activists, and individuals with low levels of political activity). As these two profiles were deemed necessary to offer a full account of the contributions of Facebook to political participation, a further snowballing procedure was added. In line with current guidelines for the definition of size of qualitative samples (Guest et al. 2006), a total of 26 interviews - thirteen for the BS and thirteen for the IS - were held. 


\section{Results}

RQ1: How does the contribution of Facebook to political participation vary in relation to preexisting levels of political activity?

In order to examine how the contribution of Facebook to political participation varies in relation to pre-existing levels of political activity, the links between Facebook, Internet and offline political participation were examined through a correlation analysis. This was the first step in assessing the tendency of Facebook to reinforce existing patterns of participation, or, rather, to promote the participation of new audiences.

\begin{tabular}{c|c|c|} 
& Internet political & Offline political \\
participation & participation \\
participation $\quad$ Sig. (2-tailed) & $0.733^{*}$ & $0.660^{*}$ \\
\hline $\begin{array}{c}\text { British Sample Facebook political Correlation coefficient } \\
\text { participation }\end{array}$ & 0.000 & 0.000 \\
\hline
\end{tabular}

* Correlation is significant at the 0.01 level (2-tailed).

Table 3: Facebook, Internet and offline political participation: Correlation analysis Spearman's $\rho$. 
As it can be seen in Table 3 the results confirm a strong link between Facebook, the Internet and the offline world in terms of political participation. However, correlation analysis does not highlight the directions of associations, and, therefore, these findings could back up both the mobilization and reinforcement hypotheses. On the one hand, they could mean that citizens who are already politically active offline and on other online platforms extend their participation to Facebook. On the other hand it could also be that citizens with limited levels of political participation started to engage politically on Facebook and then moved to other channels.

The qualitative phase played a crucial role in shedding light on this particular issue. The interviews mostly confirmed the reinforcement hypothesis, but also provided some evidence in support of the mobilization hypothesis. Facebook clearly aided the participation of citizens who were already politically active. At the same time, this SNS appeared to be able to facilitate the participation of individuals who were less politically active either because they lacked the motivation, or were limited by their health condition, or simply were not aware of participation opportunities. Nonetheless, a minimum level of political interest seemed to be required in order for someone to participate at all, and the interviews indicated that the use of Facebook alone was not able to trigger the participation of individuals who were politically apathetic.

[Relevance of political interest]

Vincent ${ }^{3}$ - British Participant (BP): 'I do keep in touch with old friends, university friends, school friends on Facebook, but mostly I use it for politics because this is what I'm interested in and most of my friends are interested in'. 
Ellie - BP: '[Among my Facebook friends I have] some people who are interested in politics. [They] sometimes [post] comments, but [...] I don't read them that much because I'm not interested in it'.

[Involving new participants]:

Tracey - BP: 'People who do have bad asthma may not be able to go out and meet other people and talk about [politics]. [Facebook can] provide them with a means of accessing information that otherwise are not going to get'.

Antonio - Italian Participant (IP): ‘[Through Facebook] you can definitely reach a larger audience [...] [During political rallies] I met many young people who I had never seen before and who told me that they got to know about these initiatives only because of Facebook'. ${ }^{4}$

The mechanisms by which Facebook can promote political participation were explored through the qualitative data. The thematic analysis of the interviews indicated that the greatest political affordance of this SNS is a practical one, namely the potential it offers for lowering the thresholds of participation.

[Facilitating participation]:

Hazel - BP: 'I will attend meetings and things, but when I either haven't got the time to attend a meeting or I feel tired I can still get involved because I can just log into Facebook'. 
Interviews also suggested a second reason that could explain the capacity Facebook has for fostering political participation. The communicative and informative power of this SNS can expose users, often accidentally through the News Feed, to political information on a daily basis, and promote political interest and knowledge. This process can activate a virtuous circle and lead to engagement in more resource-demanding forms of participation. This political affordance of Facebook seemed to hold particular relevance for the mobilization of users displaying limited levels of political participation.

[Bringing politics into everyday life]:

Tracey - BP: '[Facebook] very much brought [politics] into my everyday life, rather than only being interested in politics during election time or local elections. I think it is more of a day-to-day thing'.

[Accidental exposure to political information]:

Mario - IP: 'Facebook provides [information] as soon as you log in. Even if you don't want you see this information. This information is imposed, in the sense that you don't look anymore for information but the information is there and you see it'.

[Virtuous circle]:

Hazel - BP: '[Facebook] made me more aware politically, and by making me more aware I then felt that I had to make other people more aware [...] I have also signed up to the Labour party, which is something I would never have dreamt of before'.

Helen - BP: 'I have only recently started to become politically active on Facebook, I haven't always been [...] Maybe because I was new to it, I didn't have many 
friends. I think it's important having friends who post political information to get you interested in that'.

In summary, quantitative and qualitative data indicated that, in both samples, individuals displaying high levels of political activity on other online platforms and offline were also more likely to use Facebook to participate and engage in politics. However, in rare cases, Facebook also seemed to operate as an activator of the political participation process, promoting the involvement of citizens who had limited levels of political participation either because they lacked motivation, were restrained by health issues, or simply were not aware of participation opportunities. The two main affordances of Facebook in terms of political participation which emerged from the interviews are its capacity to make participation easier, and to convey political information to less engaged users, promoting their political interest and producing, ultimately, a mobilization effect.

RQ2: How does the contribution of Facebook vary in relation to two different dimensions of political activity - namely, political expression and information vs political mobilization?

The first step in assessing potential variations in the contribution of Facebook to political expression/information and mobilization was comparing the samples' scores related to these two dimensions. 


\begin{tabular}{|c|c|c|c|c|}
\hline & \multicolumn{2}{|c|}{ British sample } & \multicolumn{2}{|c|}{ Italian sample } \\
\hline & Median & IQR & Median & IQR \\
\hline $\begin{array}{l}\text { Facebook political } \\
\text { mobilization }\end{array}$ & 5 & 5 & 10 & 9 \\
\hline $\begin{array}{l}\text { Facebook political } \\
\text { expression/information }\end{array}$ & 10 & 10 & 15 & 10 \\
\hline Internet political mobilization & 5 & 5 & 7 & 6 \\
\hline $\begin{array}{l}\text { Internet political } \\
\text { expression/information }\end{array}$ & 11 & 8 & 12 & 8 \\
\hline Offline political mobilization & 5 & 3 & 8 & 7 \\
\hline $\begin{array}{l}\text { Offline political } \\
\text { expression/information }\end{array}$ & 11 & 8 & 13 & 9 \\
\hline
\end{tabular}

Table 4: Political mobilization vs expression and information: Descriptive statistics*.

* 5 (Never), 10 (Rarely), 15 (Sometimes), 20 (Often), 25 (Very often). 

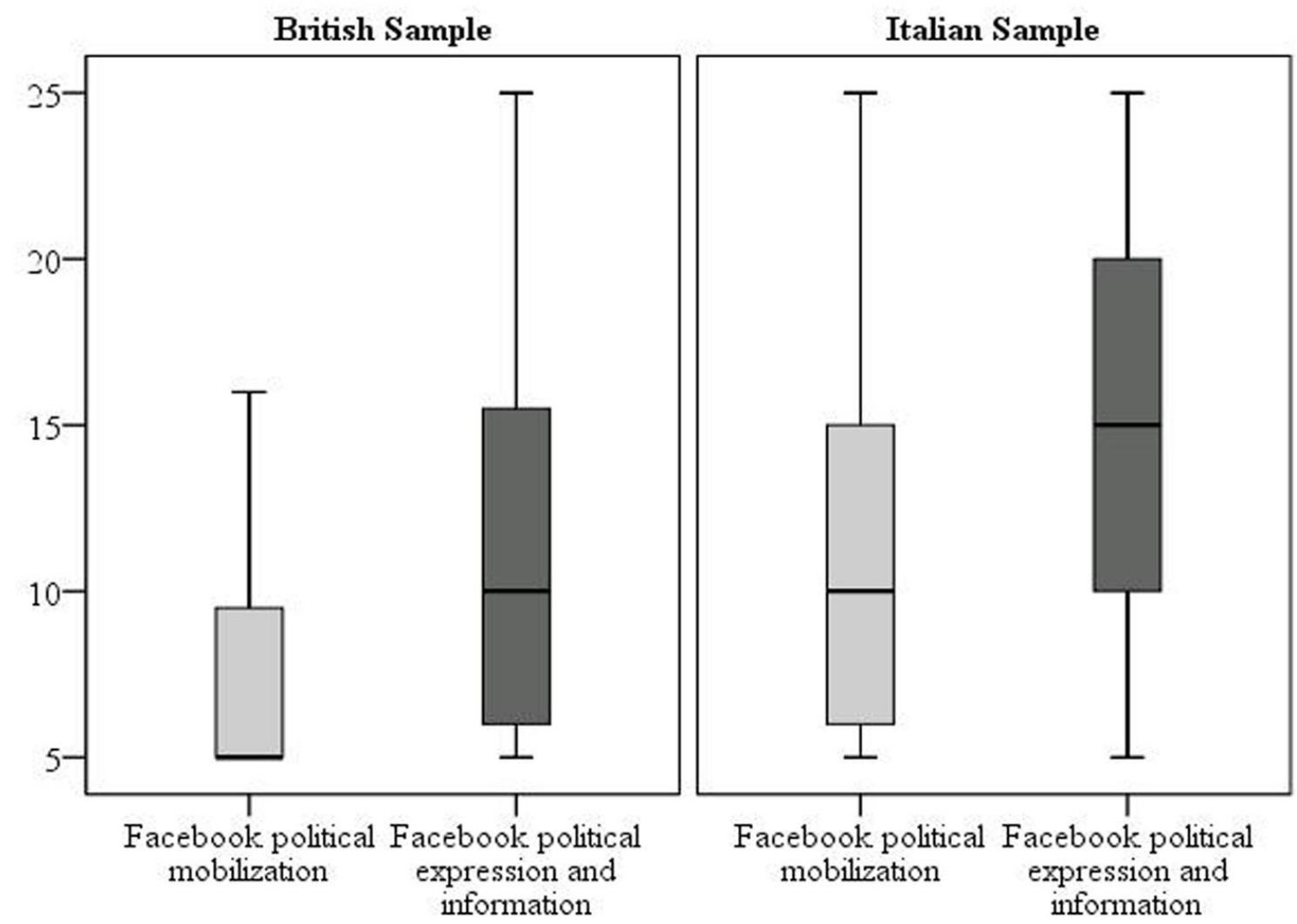

Figure 1: Political mobilization vs expression and information: Box plots*.

* 5 (Never), 10 (Rarely), 15 (Sometimes), 20 (Often), 25 (Very often).

Table 4 and Figure 1 show that both samples displayed limited levels of political participation on Facebook and that IPs were slightly more active than BPs. However, the reasons behind such a participatory discrepancy are not explored as they are out of the remit of this article. With regards to the differences between the expression/information and mobilization dimensions, both samples score higher on the political expression/information scales, a result that could suggest that Facebook contributes more to this particular dimension. However, considering that the tendency to engage more often in this type of activity was replicated in the other channels of participation, this notion was further explored in the qualitative phase. 
The thematic analysis of the interviews offered two explanations for the quantitative findings. The first is that participants engaged more often in activities falling within the expression and information dimension because they required fewer resources (e.g. less time-consuming). The second is the samples' scepticism towards the efficacy of political initiatives such as protests or rallies. Indeed, qualitative data strongly confirmed the existence of a detachment from traditional political institutions and institutionalized forms of political participation.

[Detachment from traditional politics]:

Callum - BP: 'When [the government] makes decisions that I disagree with [...] I don't think there is very much I can do about them [...] So I suppose in a sense I feel that marching won't really make a difference'.

Mario - IP: 'I feel strongly detached from institutional politics [...] it is a common feeling, the so-called anti-politics, which in my opinion is not really anti-politics but rather a disaffection towards the political class'.

Considering this political disenchantment and the required resources for mobilization activities, qualitative data indicated that the contributions of Facebook to the mobilization dimension tend to be limited to politically active individuals, with less politically active citizens employing this SNS mainly for political expression/information activities. 
[More expression/information than mobilization]:

Martina - IP: '[Facebook appears to be more useful] in terms of communication. I don't know to what extent it can lead to the involvement in a political campaign [...] [Many] people don't go beyond their PCs. It is a huge step to pass from there to a square'.

In terms of the contribution of Facebook to the mobilization dimension of political participation, interviews with British and Italian activists (i.e. individuals who displayed high levels of political mobilization) attested to the relevance of Facebook in activists' political repertoires. In both samples activists stressed how Facebook has become a central, sometimes primary, tool for the organization of political initiatives, a tool particularly suitable to single-issue campaigning.

[Growing relevance of Facebook in activists' repertoires]:

Alastair - BP: '[Facebook] has become a more an integral part of a campaign. When I was involved in one election campaign, even few years ago, it was very traditional, whereas as soon as more recent campaigns happened the first thing we did was to assign a social media person'.

Francesca - IP: '[Within activist groups] Facebook has become the main means of communication - also because you can use it on mobiles as well as on computers, it is the fastest and cheapest method of communication'. 
When discussing their political usage of Facebook, both British and Italian activists stressed the relationship between Facebook and offline participation, describing political activity on Facebook as rooted in and supporting their offline activity. Their comments support what argued by Dahlgren who observes that: 'the more political participation becomes exclusively or even largely a screen-based experience, the less effective it ultimately becomes' (2014: 266). Some participants also commented on the capacity that Facebook has to boost their own mobilization by exposing them to more information on political initiatives. This information was often related to local rather than national events, reaching them through grassroots channels, thus bypassing traditional political institutions such as parties or trade unions.

[Interdependence between Facebook and offline political participation]:

Francesca - IP: 'Facebook supports political entities which already exist $[\ldots]$ the online cannot exist without the offline'.

Mario - IP: '[Facebook] participation is the cause, the organization, while the effect needs to be offline participation'.

[Promoting grassroots single-issue mobilization]: Vincent - BP: 'Facebook has given much more ability to ordinary people who aren't affiliated to any bureau organization to organize things for themselves $[\ldots]$ So politics, political organization has become more of a grassroots thing'.

In conclusion, both samples engaged more often in political expression/information activities than in mobilization ones, a trend confirmed in all the three participation channels. The 
qualitative data suggested two main reasons behind such a difference. The first is that activities falling within the expression/information dimension are less resource-expensive (e.g. less demanding in terms of time) than the political mobilization ones. The second reason is the scepticism shown by BPs and IPs towards the efficacy of political initiatives, with participants expressing disenchantment and distrust towards the political establishment and doubting its responsiveness to their actions.

The qualitative data revealed that, given the costs in terms of resources and the perception of inefficacy of mobilization activities, the contribution of Facebook to the mobilization dimension tends to remain limited to participants who are already politically active. Facebook emerged as a key tool in activists' political repertoires, often replacing other online platforms and offline methods used to communicate, organize and promote political initiatives.

\section{Discussion: Information-led mobilization}

This article aims to contribute to the debate between Internet optimists, normalizers and pessimists, by stating that the contribution of Facebook to political participation varies in relation to pre-existing levels of political participation, and the considered dimensions of political activity, as, for example, mobilization vs expression/information.

Quantitative and qualitative results indeed revealed that these two issues are strictly interrelated, suggesting that politically active individuals are the ones who take more advantage of the 
mobilization affordances of Facebook, whereas less politically active participants employ this SNS mainly as a communicative and informative political tool.

The value of these findings is confirmed by several investigations that consider the multidimensionality of political participation. For instance, Kavanaugh et al. (2008) establish that citizens with medium/low levels of political engagement participate much less than politically active citizens in online formal political activities such as contacting public officials or donating to campaigns. However, both groups show similar levels of participation with regards to news consumption and political discussion. A similar picture also emerges in relation to SNSs by combining the investigations of Storsul (2014) and Vitak et al. (2011). Storsul (2014) reveals that these platforms are crucial for organizing and coordinating political activities, while Vitak et al. (2011) show that young people engage on Facebook mostly in activities falling within the expression/information dimension of political participation, such as expressing political opinions. Such an inconsistency can be explained by the fact that Storsul (2014) focuses on politically active youths, while Vitak et al. (2011) look into young people in general. This is in line with the findings of the research discussed in this article, which suggest that these two different groups may use SNSs in different ways: politically active youths taking advantage of the mobilization affordances of these online platforms and young people in general limiting their participation to expression/information activities.

Hence, it appears that the main contribution of Facebook to political participation, in particular with regards to individuals who do not fall within the activist group, concerns the political expression/information dimension. However, the fact that Facebook tends to contribute mainly to such a dimension of political participation does not have to be undervalued. Numerous studies emphasize the links between political expression/information activities on SNSs and other forms 
of political participation (including offline participation), with consumption of political information often leading to more active forms of political participation (Enjolras et al. 2012; Copeland and Bimber 2015; Gustafsson 2012; Hamilton and Tolbert 2012; Rojas and Puig-iAbril 2009; Towner 2013). The findings of the research discussed in this article suggest that, through either direct selection or accidental exposure, Facebook can contribute to the diffusion of political information and potentially activate a virtuous circle, 'a ratcheting process that over the long term gradually reinforces the activism of the active' (Norris 2000: 309). Moreover, the findings suggest that this could generate information-led mobilization and that the virtuous circle goes beyond politically active individuals, applying also to less politically engaged users.

In relation to the mobilization dimension, the research showed that Facebook is a key tool for activists in that, as confirmed in a number of studies (Khamis and Vaughn 2012; Obar et al. 2012; Storsul 2014; Valenzuela et al. 2012; Vromen et al. 2015; Warren et al. 2014), it can aid their mobilization efforts by offering additional venues of participation, facilitating the organization and promotion of political initiatives, and enlarging their political networks.

This article establishes that individuals' political interest remains crucial in triggering participation. Therefore, it provides strong support to the normalizers' stance and suggests that, as a political platform, Facebook aids mostly individuals who are already politically active. Similarly to the tendency of Facebook to support mainly political expression/information activities in the case of less politically active users, this finding should not be perceived in a negative light, as it is by the advocates of the rich-get-richer hypothesis (e.g. Bonfadelli 2002; Schlozman et al. 2010). In fact, as Curtice and Norris (2008) and Vaccari et al. (2013) also indicate, the activities of political activists can have an indirect effect on less politically engaged individuals, in turn encouraging their participation. 
The findings of the present research demonstrate that such an indirect effect can occur on Facebook too, with the broadcasting-style affordances of this SNS playing a crucial role in this instance. Pedroni et al. (2014) note that Facebook exhibits features surprisingly consistent with mass media models, in terms of passivity, content production and content consumption. This article substantiates this claim and highlights its consequences for political participation. By exposing, often accidentally, its users to other contacts' political activities through the News Feed, Facebook can stimulate political interest and lead to the participation of less politically active users.

The links between accidental exposure to information and political participation are highlighted in several studies. Bond et al. (2012), Morris and Morris (2013) and Copeland and Bimber (2015) examined political participation during the 2012 US Presidential campaign and showed that accidental exposure to political information could exert a mobilizing influence. Particularly relevant to the findings discussed in this article is Gustafsson's (2012) claim that many nonorganized Facebook users - even if they do not actively participate in political discussions or other political activities themselves - are still affected by other users' recruitment attempts and the information shared by others, and what is described by Hamilton and Tolbert (2012) as 'accidental mobilization'.

The study that informed this article thus backs up the normalizers' arguments, but also provides evidence in support of the mobilization hypothesis, with the mobilization of less-politically active participants occurring as a consequence of their engagement in expression/information activity, i.e. information-led mobilization, or endorsed by the actions of politically active individuals who can operate as participation intermediaries. 


\section{Conclusions}

Drawing from an extensive and unique data set acquired by combining a cross-national approach and mixed methods, this article examines the contribution of Facebook to citizens' political participation in Italy and the United Kingdom. It finds that Facebook can further increase the political activity of politically active citizens by offering additional venues of participation. At the same time, it shows that this SNS can aid users with limited levels of political participation by reducing the thresholds of participation and exposing them to more political information and participation opportunities.

Furthermore, distinguishing between political mobilization and expression/information, the article determines that the contribution of Facebook to political participation varies in relation to the different dimensions of undertaken political activity. Politically active participants are those who take more advantage of the mobilization affordances of Facebook, whereas less politically active participants employ this SNS mainly as a communicative and informative political tool.

The study complements the work of other researchers who also find that digital technologies have dual effects on political participation (Bimber et al. 2015; Gibson and Cantijoch 2013; Nam 2012), adding to and refining an existing commentary. It establishes that the effects of digital technologies on political participation are manifold - reinforcement does not exclude mobilization and vice versa - and must be assessed as part of a continuum, rather than being considered in neat, mutually exclusive categories.

This article, hence, demonstrates beyond doubt the sterility of the dispute between optimists, normalizers, and pessimists. Furthermore, it advocates for the adoption of a more particularized 
approach, which offers further discriminatory power by acknowledging the multidimensionality of political participation and distinguishing between different participatory modes.

\section{References}

Ancu, Monica and Cozma, Raluca (2009), 'MySpace politics: Uses and gratifications of befriending candidates', Journal of Broadcasting \& Electronic Media, 53:4, pp. 567-83.

Anduiza, Eva, Cantijoch, Marta and Gallego, Aina (2009), 'Political participation and the Internet: A field essay', Information, Communication \& Society, 12:6, pp. 860-78.

Atkeson, Lonna R. (2010), 'The state of survey research as a research tool in American politics', in Jan E. Leighley (ed.), The Oxford Handbook of American Elections and Political Behavior, Oxford: Oxford University Press, pp. 9-27.

Bachmann, Ingrid and Gil de Zúñiga, Homero (2013), 'News Platform Preference as a predictor of political and civic participation', Convergence: The International Journal of Research into New Media Technologies, 19:4, pp. 496-512. 
Baek, Young Min (2015), 'Political mobilization through social network sites: The mobilizing power of political messages received from SNS friends', Computers in Human Behavior, $44: 1$, pp. $12-19$.

Baumgartner, Jody C. and Morris, Jonathan S. (2010), 'MyFaceTube politics: Social networking web sites and political engagement of young adults', Social Science Computer Review, 28:1, pp. 24-44.

Bennett, W. Lance (1998), 'Ithiel de Sola Pool lecture: The UnCivic culture: Communication, identity, and the rise of lifestyle politics', P.S.: Political Science and Politics, 31:1, pp. $41-61$.

Bennett, W. Lance and Segerberg, Alexandra (2012), 'The logic of connective action: Digital media and the personalization of contentious politics', Information, Communication \& Society, 15:5, pp. 739-68.

Berlo, David K. (1960), The Process of Communication: An Introduction to Theory and Practice, New York, NY: Holt, Rinehart and Winston.

Bhutta, Christine Brickman (2012), 'Not by the book: Facebook as a sampling frame', Sociological Methods \& Research, 41:1, pp. 57-88. 
Bimber, Bruce (2001), 'Information and political engagement in America: The search for effects of information technology at the individual level', Political Research Quarterly, 54:1, pp. 53-67.

Bimber, Bruce, Cantijoch Cunill, Marta, Copeland, Lauren and Gibson, Rachel (2015), 'Digital media and political participation: The moderating role of political interest across acts and over time', Social Science Computer Review, 33:1, pp. 21-42.

Bond, Robert, Fariss, Christopher, Jones, Jason, Kramer, Adam, Marlow, Cameron, Settle, Jaime and Fowler, James (2012), 'A 61-million-person experiment in social influence and political mobilization', Nature, 489:7415, pp. 295-97.

Bonfadelli, Heinz (2002), 'The Internet and knowledge gaps: A theoretical and empirical investigation', European Journal of Communication, 17:1, pp. 65-84.

boyd, m. danah and Ellison, Nicole B. (2007), 'Social network sites: Definition, history, and scholarship', Journal of Computer-Mediated Communication, 13:1, pp. 210-30.

Braun, Virginia and Clarke, Victoria (2006), 'Using thematic analysis in psychology', Qualitative Research in Psychology, 3:2, pp. 77-101. 
Brundidge, Jennifer and Rice, Ronald E. (2009), 'Political engagement online: Do the information rich get richer and the like-minded more similar?', in A. Chadwick and P. N. Howard (eds), Routledge Handbook of Internet Politics, Abingdon: Routledge, pp. 14456.

Calenda, Davide and Meijer, Albert (2009), 'Young people, internet and political participation: Findings of a web survey in Italy, Spain and The Netherlands', Information, Communication \& Society, 12:6, pp. 879-98.

Calenda, Davide and Mosca, Lorenzo (2007), 'The political use of the internet: Some insights from two surveys of Italian students', Information, Communication \& Society, 10:1, pp. $29-47$.

Carlisle, Juliet E. and Patton, Robert C. (2013), 'Is social media changing how we understand political engagement? An analysis of Facebook and the 2008 Presidential Election', Political Research Quarterly, 66:4, pp. 883-95.

Chadwick, Andrew and Howard, Philip N. (eds) (2009), Routledge Handbook of Internet Politics, Abingdon: Routledge. 
Christy, Carol A. (1987), Sex differences in Political Participation: Processes of Change in Fourteen Nations, New York, NY: Praeger.

Copeland, Lauren and Bimber, Bruce (2015), 'Variation in the relationship between digital media use and political participation in U.S. elections over time, 1996-2012: Does Obama's reelection change the picture?', Journal of Information Technology \& Politics, $12: 1$, pp. $74-87$.

Curran, James, Coen, Sharon, Soroka, Stuart, Aalberg, Toril, Hayashi, Kaori, Hichy, Zira, Iyengar, Shanto, Jones, Paul, Mazzoleni, Gianpietro, Papathanassopoulos, Stylianos, Rhee, June Woong, Rojas, Hernando, Rowe, David and Tiffen, Rod (2014), "Reconsidering "virtuous circle" and "media malaise" theories of the media: An 11nation study', Journalism, 15:7, pp. 815-33.

Curtice, John and Norris, Pippa (2008), 'Getting the message out: A two-step model of the role of the internet in campaign communication flows during the 2005 British General Election', Journal of Information Technology \& Politics, 4:4, pp. 3-13.

Dahlgren, Peter (2009), Media and Political Engagement: Citizens, Communication, and Democracy, New York, NY: Cambridge University Press. 
(2014), 'Political participation via the web: Structural and subjective contingencies', Interactions: Studies in Communication \& Culture, 5:3, pp. 255-69.

Dalton, Russell J. (2004), Democratic Challenges, Democratic Choices: The Erosion of Political Support in Advanced Industrial Democracies, New York, NY: Oxford University Press.

Enjolras, Bernard, Steen-Johnsen, Kari and Wollebaek, Dag (2012), 'Social media and mobilization to offline demonstrations: Transcending participatory divides?', New Media \& Society, 15:6, pp. 890-908.

Fenton, Natalie and Barassi, Veronica (2011), 'Alternative media and social networking sites: The politics of individuation and political participation', The Communication Review, $14: 3$, pp. 179-96.

Gibson, Rachel K. and Cantijoch, Marta (2013), 'Conceptualizing and measuring participation in the age of the Internet: Is online political engagement really different to offline?', The Journal of Politics, 75:3, pp. 701-16.

Greene, Jennifer C., Benjamin, Lehn and Goodyear, Lesley (2001), 'The merits of mixing methods in evaluation', Evaluation, 7:1, pp. 25-44. 
Guest, Greg, Bunce, Arwen and Johnson, Laura (2006), 'How many interviews are enough? An experiment with data saturation and variability', Field Methods, 18:1, pp. 59-82.

Gustafsson, Nils (2012), 'The subtle nature of Facebook politics: Swedish social network site users and political participation', New Media \& Society, 14:8, pp. 1286-303.

Gutmann, Amy and Thompson, Dennis (1996), Democracy and Disagreement, Cambridge, MA: Harvard University Press.

Hamilton, Allison and Tolbert, Caroline J. (2012), 'Political engagement and the Internet in the 2008 U.S. Presidential Elections: A panel survey', in E. Anduiza, M. J. Jensen, L. Jorba (eds), Digital Media and Political Engagement Worldwide: A Comparative Study, Cambridge: Cambridge University Press, pp. 56-79.

Holt, Kristoffer, Shehata, Adam, Strömbäck, Jesper and Ljungberg, Elisabet (2013), 'Age and the effects of news media attention and social media use on political interest and participation: Do social media function as leveller?', European Journal of Communication, 28:1, pp. 19-34.

Jensen, Jakob L. (2013), 'Political participation online: The replacement and the mobilisation hypotheses revisited', Scandinavian Political Studies, 36:4, pp. 347-64. 
Kavanaugh, Andrea, Kim, B. Joon, Perez- Quiñones, Manuel A., Schmitz, Joseph and Isenhour, Philip (2008), 'Net gains in political participation: Secondary effects of Internet on community', Information, Communication \& Society, 11:7, pp. 933-63.

Kenski, Kate and Stroud, Natalie J. (2006), 'Connections between Internet use and political efficacy, knowledge, and participation', Journal of Broadcasting \& Electronic Media, 50:2, pp. 173-92.

Khamis, Sahar and Vaughn, Katherine (2012), “We are all Khaled Said": The potentials and limitations of cyberactivism in triggering public mobilization and promoting political change', Journal of Arab \& Muslim Media Research, 4:2-3, pp. 145-63.

Kim, Joohan and Kim, Eun Joo (2008), 'Theorizing dialogic deliberation: Everyday political talk as communicative action and dialogue', Communication Theory, 18:1, pp. 51-70.

Krueger, Brian S. (2006), 'A comparison of conventional and Internet political mobilization', American Politics Research, 34:6, pp. 759-76.

Lynn, Peter (2003), 'Developing quality standards for cross-national survey research', International Journal of Social Research Methodology, 6:4, pp. 323-36. 
Lynn, Peter, Häder, Sabine, Gabler, Siegfried and Laaksonen, Seppo (2007), 'Methods for achieving equivalence of samples in cross-national surveys: The European social survey experience', Journal of Official Statistics, 23:1, pp. 107-24.

Milliman, John and Von Glinow, Mary A. (1998), 'Research and publishing issues in large scale cross-national studies', Journal of Managerial Psychology, 13:3/4, pp. 137-42.

Morris, David S. and Morris, Jonathan S. (2013), 'Digital inequality and participation in the political process: Real or imagined?', Social Science Computer Review, 31:5, pp. 589600.

Moy, Patricia, Manosevitch, Edith, Stamm, Keith and Dunsmore, Kate (2005), 'Linking dimensions of Internet use and civic engagement', Journalism and Mass Communication Quarterly, 82:3, pp. 571-86.

Nam, Taewoo (2012), 'Dual effects of the internet on political activism: Reinforcing and mobilizing', Government Information Quarterly, 29:1, pp. 90-97.

Nisbet, Matthew C. and Scheufele, Dietram A. (2004), 'Political talk as a catalyst for online citizenship', Journalism \& Mass Communication Quarterly, 81:4, pp. 877-96. 
Norris, Pippa (2000), A Virtuous Circle: Political Communications in Post-Industrial Democracies, Cambridge: Cambridge University Press.

(2002), Democratic Phoenix: Reinventing Political Activism, New York, NY: Cambridge University Press.

(2011), Democratic Deficit: Critical Citizens Revisited, New York, NY: Cambridge University Press.

Obar, Jonathan A., Zube, Paul and Lampe, Cliff (2012), 'Advocacy 2.0: An analysis of how advocacy groups in the United States perceive and use social media as tools for facilitating civic engagement and collective action', Journal of Information Policy, 2:1, pp. 1-25.

Papacharissi, Zizi (2010), A Private Sphere: Democracy in a Digital Age, Cambridge: Polity Press.

Pedroni, Marco, Pasquali, Francesca and Carlo, Simone (2014), “"My Friends are my Audience": Mass mediation of personal content and relations in Facebook', Observatorio 
(OBS) Journal, 8:3, pp. 97-113, http://obs.obercom.pt/index.php/obs/article/view/739. Accessed 13 January 2015.

Quintelier, Ellen (2007), 'Differences in political participation between young and old people', Contemporary Politics, 13:2, pp. 165-80.

Rojas, Hernando and Puig-i-Abril, Eulalia (2009), 'Mobilizers mobilized: Information, expression, mobilization and participation in the digital age', Journal of ComputerMediated Communication, 14:4, pp. 902-27.

Scheufele, Dietram A. and Nisbet, Matthew C. (2002), 'Democracy online: New opportunities and dead ends', Harvard International Journal of Press/Politics, 7:3, pp. 53-73.

Schlozman, Kay L., Verba, Sydney and Brady, Henry E. (2010), 'Weapon of the strong? Participatory inequality and the Internet', Perspectives on Politics, 8:2, pp. 487-509.

Segatti, Paolo (2006), 'Italy, forty years of political disaffection. A longitudinal exploration', in M. Torcal and J. R. Montero (eds), Political Disaffection in Contemporary Democracies: Social Capital, Institutions and Politics, London: Routledge, pp. 244-76. 
Socialbakers (2012), 'Facebook statistics by Nation', http://www.socialbakers.com. Accessed 10 June 2012.

Storsul, Tanja (2014), 'Deliberation or self-presentation? Young people, politics and social media', Nordicom Review, 35:2, pp. 17-28.

Stromer-Galley, Jennifer (2003), 'Diversity of political conversation on the Internet: Users' perspectives', Journal of Computer-Mediated Communication, 8:3, http://onlinelibrary.wiley.com/doi/10.1111/j.1083-6101.2003.tb00215.x/full. Accessed 30 June 2016.

Towner, Terri L. (2013), 'All political participation is socially networked? New media and the 2012 election', Social Science Computer Review, 31 5, pp. 527-41.

Vaccari, Cristian, Valeriani, Augusto, Barberá, Pablo, Bonneau, Richard, Jost, John T., Nagler, Jonathan and Tucker, Joshua A. (2013), 'Social media and political communication: A survey of Twitter users during the 2013 Italian general election', Rivista Italiana di Scienza Politica, 43:3, pp. 381-410.

Valenzuela, Sebastián (2013), 'Unpacking the use of social media for protest behavior: The roles of information, opinion expression, and activism', American Behavioral Scientist, 57:7, pp. $920-42$. 
Valenzuela, Sebastián, Arriagada, Arturo and Scherman, Andrés (2012), 'The social media basis of youth protest behavior: The case of Chile', Journal of Communication, 62:2, pp. 299314.

Valenzuela, Sebastián, Park, Namsu and Kee, Kerk F. (2009), 'Is there social capital in social network site?: Facebook use and college students' life satisfaction, trust, and participation', Journal of Computer-Mediated Communication, 14:4, pp. 875-901.

Van Deth, Jan W., Montero, Jose Ramon and Westholm, Anders (2007), Citizenship and Involvement in European Democracies: A Comparative Analysis, New York, NY: Routledge.

Verba, Sidney, Brady, Henry E. and Schlozman, Kay L. (1995), Voice and Equality: Civic Voluntarism in American Politics, Cambridge, MA: Harvard University Press.

Vesnic-Alujevic, Lucia (2012), 'Political participation and web 2.0 in Europe: A case study of Facebook', Public Relations Review, 38:3, pp. 466-70. 
Vitak, Jessica, Zube, Paul, Smock, Andrew, Carr, Caleb T., Ellison, Nicole and Lampe, Cliff (2011), 'It's complicated: Facebook users' political participation in the 2008 election', Cyberpsychology, Behavior, and Social Networking, 14:3, pp. 107-14.

Vromen, Ariadne, Xenos, Michael A. and Loader, Brian D. (2015), 'Young people, social media and connective action: From organisational maintenance to everyday political talk', Journal of Youth Studies, 18:1, pp. 80-100.

Warren, Anne M., Sulaiman, Ainin and Jaafar, Noor I. (2014), 'Facebook: The enabler of online civic engagement for activists', Computers in Human Behavior, 32:1, pp. 284-89.

Whiteley, Paul (2012), Political Participation in Britain: The Decline and Revival of Civic Culture, Basingstoke: Palgrave Macmillan.

Xenos, Michael A., Vromen, Ariadne and Loader, Brian D. (2014), 'The great equalizer? Patterns of social media use and youth political engagement in three advanced democracies', Information, Communication \& Society, 17:2, pp. 151-67.

Zhang, Weiwu and Chia, Stella C. (2006), 'The effects of mass media use and social capital on civic and political participation', Communication Studies, 57:3, pp. 277-97. 


\section{Contributor details}

Dr Isidoropaolo Casteltrione, Ph.D., is a lecturer and researcher in the Media, Communication and Performing Arts division at Queen Margaret University, Edinburgh. His research projects, lectures, seminars and workshops focus on new media and politics, digital and converged media, media systems, political communication, public relations, dialogue and research methods.

\section{Contact:}

Media, Communication and Performing Arts Division, Queen Margaret University, EH21 6UU, Edinburgh, United Kingdom.

E-mail: icasteltrione@qmu.ac.uk

\section{Notes}

${ }^{1}$ Formal political discussion is intended in this article as a deliberative process in which actors operate together, they mutually respect and listen to each other, present their arguments reasonably and are willing to revise their initial stances (Gutmann and Thompson 1996). Differently, informal political discussion refers to what has been described in the literature as 'political talk', namely a 'non-purposive, informal, casual, and spontaneous political conversation voluntarily carried out by free citizens, without being constrained by formal procedural rules and predetermined agenda' (Kim and Kim 2008: 54).

${ }^{2}$ While formal and informal political discussions entail an interaction between two or more actors, expressing a political opinion is a simple communicative act, e.g. posting a status update on Facebook, and does not require interaction with other individuals.

${ }^{3}$ Fictional names are used in order to protect participants' privacy and anonymity.

${ }^{4}$ Interviews with IPs were conducted in Italian and quotes were translated to English by the author. 